\title{
Comparison between 1-compartmental and 2-compartmental model in calculation of myocardium blood flow in ${ }^{82} \mathrm{Rb}$ PET imaging
}

\author{
Karin Knesaurek, J osef Machac \\ Division of Nuclear Medicine, the Mount Sinai Medical Center, New York, USA
}

Correspondence: Karin Knesaurek. Address: Division of Nuclear Medicine. Box 1141. One Gustave Levy Place, New York, NY, 10029, USA. Telephone: 12-122-419-368. Fax: 12-128-312-851. E-mail: karin.knesaurek@mountsinai.org

Received: November 8, $2011 \quad$ Accepted: December 28, 2011 Published: June 1, 2012

DOI : 10.5430/jbgc.v2n1p39 URL: http://dx.doi.org/10.5430/jbgc.v2n1p39

\section{Abstract}

Objective: To the best of our knowledge, no comparison between 1-compartmental $(1 \mathrm{~cm})$ and 2-compartmental $(2 \mathrm{~cm})$ models in calculation of myocardium blood flow (MBF) and coronary flow reserve (CFR) in ${ }^{82} \mathrm{Rb}$ PET imaging has been performed. We present our results of comparing $1 \mathrm{~cm}$ and $2 \mathrm{CM}$ in ${ }^{82} \mathrm{Rb}$ myocardial PET imaging.

Methods: Twenty nine patients, mean age $58 \pm 9.5$ years (mean \pm standard deviation), were imaged at rest and pharmacological stress, following an i.v. injection of $1850 \mathrm{MBq}$ of ${ }^{82} \mathrm{Rb}$ each. A GE DLS PET-CT+16 scanner was used in this study. All images were acquired in 2D mode. For each study, 50 frames were acquired. The time per frame was 5 sec between 0-3 min, 15sec between 3-5 min and $30 \mathrm{sec}$ between 5-8 min. MBF was calculated by using $1 \mathrm{~cm}$ and $2 \mathrm{~cm}$. The results for global and regional left circumflex artery (LCX), left anterior artery (LAD) and right coronary artery (RCA), rest and stress MBF, and CFR values obtained by $1 \mathrm{~cm}$ and $2 \mathrm{~cm}$ were compared by using Bland and Altman method. The reproducibility coefficient was calculated as 1.96 times the standard deviation (SD) of the differences between $1 \mathrm{~cm}$ and $2 \mathrm{~cm}$ values.

Results: The global rest MBF values, expressed as mean \pm SD, for both $1 \mathrm{~cm}$ and $2 \mathrm{~cm}$ were very similar $(0.74 \pm 0.17$ vs. $0.73 \pm 0.17 \mathrm{~mL} / \mathrm{min} / \mathrm{g})$, and reproducibility was good, $0.12 \mathrm{~mL} / \mathrm{min} / \mathrm{g}(16.3 \%$ of the mean). The same held true for the $1 \mathrm{CM}$ and $2 \mathrm{CM}$ stress global MBF values $(1.71 \pm 0.54$ and $1.73 \pm 0.50 \mathrm{~mL} / \mathrm{min} / \mathrm{g})$ with good reproducibility of 0.25 $\mathrm{mL} / \mathrm{min} / \mathrm{g}$ (14.4\% of the mean). The regional, LCX, LAD and RCA rest and stress MBF values, obtained by $1 \mathrm{~cm}$ and $2 \mathrm{~cm}$, were marginally reproducible, i.e., $50 \%$ or more of the mean. The global CFR values for both $1 \mathrm{~cm}$ and $2 \mathrm{~cm}$ were very similar ( $2.44 \pm 0.84$ vs. $0.2 .44 \pm 0.89$ ), and reproducibility was good 0.34 ( $14.1 \%$ of the mean).

Conclusions: The MBF and CFR global rest and stress values obtained by $1 \mathrm{~cm}$ and $2 \mathrm{~cm}$ were close and reproducible. However, the regional LAD, RCA and LCX rest and stress MBF values showed marginal reproducibility. Limited regional MBF reproducibility may be caused by sampling error and/or cardiac and breathing motion. We believe that the reproducibility of regional values can be improved by data smoothing and motion gating.

\section{Key words}

Myocardial blood flow (MBF), Coronary flow reserve (CFR), ${ }^{82} \mathrm{Rb}$ myocardial PET imaging 


\section{Introduction}

Over the past decade, a shortage of ${ }^{99 \mathrm{~m}}$ Tc cardiac perfusion SPECT tracers and increased number of PET/CT scanners, revived interest for ${ }^{82} \mathrm{Rb}$ cardiac perfusion PET imaging. Especially the push for it was in Europe, where the number of myocardial perfusion imaging (MPI) studies is low compared with the number of MPI performed in the USA ${ }^{[1,2]}$. The main advantage of ${ }^{82} \mathrm{Rb}$ over other approved PET perfusion tracers, namely ${ }^{13} \mathrm{NH}_{3}$ and ${ }^{15} \mathrm{O}$-labeled water $\left(\mathrm{H}_{2}{ }^{15} \mathrm{O}\right)$, is that among these tracers only ${ }^{82} \mathrm{Rb}$ is generator-produced and does not require an onsite cyclotron. The quantification of myocardial blood flow (MBF) and coronary flow reserve (CFR) can improve diagnostic and prognostic value of MPI. MBF and CFR provide information on both the macro- and the micro-circulation and likely more accurate detection of both early and advanced disease ${ }^{[2,3]}$. However, there are several issues related to quantification of regional MBF using ${ }^{82} \mathrm{Rb}$. First, due to the short half-life of ${ }^{82} \mathrm{Rb}(75 \mathrm{~s})$, cardiac images obtained with ${ }^{82} \mathrm{Rb}$ tend to be count-poor. Second, the high positron energy (3.15 MeV) results in decreased resolution compared to other PET tracers. Third, there is heavy dependence of myocardial extraction of this tracer on the prevailing flow rate and myocardial metabolic state ${ }^{[4]}$. However, careful design of the ${ }^{82} \mathrm{Rb}$ cardiac perfusion PET imaging protocol, with proper timing and dosing, can achieve good quality images using either, 2D and 3D PET imaging ${ }^{[5]}$.

To the best of our knowledge, no comparison between 1-compartmental $(1 \mathrm{~cm})$ and 2-compartmental $(2 \mathrm{~cm})$ models in calculation of MBF and CFR in ${ }^{82} \mathrm{Rb}$ PET imaging has been performed, as was the case for ${ }^{13} \mathrm{NH}_{3}$ cardiac perfusion PET imaging ${ }^{[6]}$. In ${ }^{82} \mathrm{Rb}$ and ${ }^{13} \mathrm{NH}$-ammonia PET myocardial perfusion studies, various centers are using different approaches, i.e., $1 \mathrm{~cm}$ or $2 \mathrm{~cm}$, for estimation of MBF. In this paper, we wish to compare MBF calculations at rest and pharmacological stress, and calculation of CFR, utilizing $1 \mathrm{~cm}$ and $2 \mathrm{~cm}$ models in ${ }^{82} \mathrm{Rb}$ cardiac perfusion PET imaging.

\section{Materials and methods}

\subsection{Protocol}

Twenty nine patients, mean age $58 \pm 9.5$ years (mean \pm standard deviation), were imaged at rest and pharmacological stress, following an i.v. injection of $1850 \mathrm{MBq}$ of ${ }^{82} \mathrm{Rb}$ each. Subjects were instructed to fast for at least $6 \mathrm{~h}$ and to abstain from products containing caffeine for at least $12 \mathrm{~h}$ prior to imaging. The study protocol met the criteria of the Declaration of Helsinki, was approved by the internal review board and all subjects gave informed consent. Pharmacologic stress was achieved with the standard dose of adenosine $(140 \mathrm{mg} / \mathrm{kg} / \mathrm{min}$ infused over $6 \mathrm{~min})$ or dipyridamole $(0.56 \mathrm{mg} / \mathrm{kg}$ infused over 4 min).

\subsection{Data acquisition}

For each dynamic study, 50 frames were acquired. The time per frame was 5 sec between 0-3 min, 15sec between 3-5 min and 30 sec between 5-8 min. A GE DLS PET-CT+16 scanner (General Electric Medical Systems, Milwaukee, WI) was used for all acquisitions. All studies were done in 2D acquisition mode and images were reconstructed using a filtered back projection reconstruction method and a Hanning smoothing filter with a $0.5 \mathrm{cy} / \mathrm{cm}$ cutoff. The matrix size was $128 \times 128$ and the pixel size was $4.29 \mathrm{~mm}$. Attenuation correction was applied in all studies using 16-slice CT images. In addition, standard corrections for randoms and scatter provided by the vendor were applied.

\subsection{Data analysis}

A 1-compartmental and a 2-compartmental model were used to estimate $\mathrm{MBF}(\mathrm{mL} / \mathrm{min} / \mathrm{g})$ and coronary flow reserve (CFR). The 1CM is described with the differential equation ${ }^{[7]}$

$$
\mathrm{dC}_{\text {myo }}(t) / \mathrm{d} t=\mathrm{K}_{1} \mathrm{C}_{\mathrm{a}}(t)-\mathrm{K}_{2} \mathrm{C}_{\text {myo }}(t)
$$


where $\mathrm{C}_{\mathrm{a}}(t)$ and $\mathrm{C}_{\text {myo }}(t)$ are the concentrations of ${ }^{82} \mathrm{Rb}$ in the arterial blood and the myocardium respectively. No metabolite correction was applied in this case $\left[\mathrm{C}_{\mathrm{a}}(t)=\mathrm{C}_{\mathrm{lv}}(t)\right]$.

${ }^{82} \mathrm{Rb}$ is known to have a flow-dependent extraction fraction, so that $\mathrm{K}_{1}$, which is the product of flow MBF times extraction fraction $\mathrm{E}$, is described by a Renkin-Crone function

$$
\mathrm{K}_{1}=\left(1-\mathrm{a} * \mathrm{e}^{-\mathrm{b} / \mathrm{MBF}}\right) * \mathrm{MBF}
$$

The values of the correction factors used were $a=0.77$ and $b=0.63(\mathrm{~mL} / \mathrm{min} / \mathrm{g}){ }^{[7]}$. The model implements a geometric double spillover correction for activity from the left and right ventricle in the form:

$$
\mathrm{C}_{\mathrm{PET}}(t)=\left(1-\mathrm{V}_{\mathrm{lv}} \mathrm{V}_{\mathrm{rv}}\right) \mathrm{C}_{\mathrm{myo}}(t)+\mathrm{V}_{\mathrm{lv}} \mathrm{C}_{\mathrm{lv}}(t)+\mathrm{V}_{\mathrm{rv}} \mathrm{C}_{\mathrm{rv}}(t)
$$

where $\mathrm{V}_{\mathrm{lv}}$ is spill-over fraction of the blood activity in the left ventricle $\mathrm{Cl}_{\mathrm{v}}(t)$, and $\mathrm{V}_{\mathrm{rv}}$ is spill-over fraction of the blood activity in the right ventricle $\mathrm{C}_{\mathrm{rv}}(t)$. In practice, the equation (2) is inserted into the differential equation (1), so that MBF becomes a fit parameter, and $\mathrm{K}_{1}$ is a derived parameter. As shown in equations (1) and (3), $\mathrm{C}_{\mathrm{rv}}(t)$ and $\mathrm{C}_{\mathrm{lv}}(t)$ are used in spillover correction and $\mathrm{C}_{\mathrm{lv}}(t)$ is used as input curve.

The 2-compartmental model is described by two differential equations ${ }^{[8,9]}$

$$
\begin{gathered}
\left.\mathrm{dC}_{1}(t) / \mathrm{d} t=\operatorname{MBF}\left[\mathrm{C}_{\mathrm{a}}(t)-\mathrm{C}_{1}(t) / \mathrm{V}_{\mathrm{d}}\right)\right]-\mathrm{k}_{1} \mathrm{C}_{1}(t)+\mathrm{k}_{2} \mathrm{C}_{2}(t) \\
\mathrm{dC}_{2}(t) / \mathrm{d} t=\mathrm{k}_{1} \mathrm{C}_{1}(t)-\mathrm{k}_{2} \mathrm{C}_{2}(t)
\end{gathered}
$$

where $\mathrm{C}_{1}(t)$ represents the fast exchangeable compartment (vascular and interstitial spaces), $\mathrm{C}_{2}(\mathrm{t})$ the slow exchangeable compartment (intracellular space), $\mathrm{k}_{1}$ and $\mathrm{k}_{2}$ are rate constants $(1 / \mathrm{min})$ and $\mathrm{V}_{\mathrm{d}}$ is a fractional volume of distribution in the first compartment.

The operational equation which is fitted to the measured data is

$$
\mathrm{C}_{\mathrm{PET}}(t)=\mathrm{FMM}\left[\mathrm{C}_{1}(t)+\mathrm{C}_{2}(t)\right]+\mathrm{FBMC}_{\mathrm{a}}(t)
$$

where FMM denotes the tissue recovery coefficient and FBM denotes the blood to myocardium spillover fraction.

The recovery coefficient (FMM) was set to 0.65 , and the fractional volume of the first compartment $\left(\mathrm{V}_{\mathrm{d}}\right)$ was fixed at 0.75 $\mathrm{mL} / \mathrm{mL}^{[8]}$. The differential equations (5) and (6), describing a 2-compartmental model, were solved by numerical integration and using Levenberg-Marquardt's method for fitting data. The program calculates flow values (mL/min/mL), $\mathrm{k}_{1}$ and $\mathrm{k}_{2}$ constants and cross-talk from blood to tissue (FMB).

\section{Creation of volume-of interests (VOIs) and time-activity-curves (TACs)}

The first step in creation of the left ventricle (LV), right ventricle (RV), and myocardial VOIs was to sum dynamic study. The summed study was then re-oriented to short-axis orientation. The initial VOIs were obtained from re-oriented summed myocardial images using the PMOD program ${ }^{[10,11]}$, which had been used before for the assessment of MBF with rest and stress in ${ }^{15}$ O-labeled water PET studies ${ }^{[11]}$. However, for more than a half subjects, a skilled operator corrected initial VOIs by drawing slightly different region-of interests (ROIs) over several slices of the 3-dimensional (3D) volume (see Figure 1). The corrected VOIs were then used to obtain the left ventricle (LV), right ventricle (RV), and 17 segments myocardial TACs. The current PMOD version 3.2 uses American Heart Association 17 standard segments and calculates myocardial flow for each segment, as well as average left circumflex artery (LCX), left anterior artery (LAD) and right coronary artery (RCA) territories, and global flow (see Figure 2). 
Figure 1. The left ventricular (LV), right ventricular (RV), and myocardial VOIs were created by drawing regions-of-interests (ROIs) over several slices of the 3-dimensional (3D) volume. The VOIs were then used in the original dynamic study in order to create time-activity-curves (TAC).

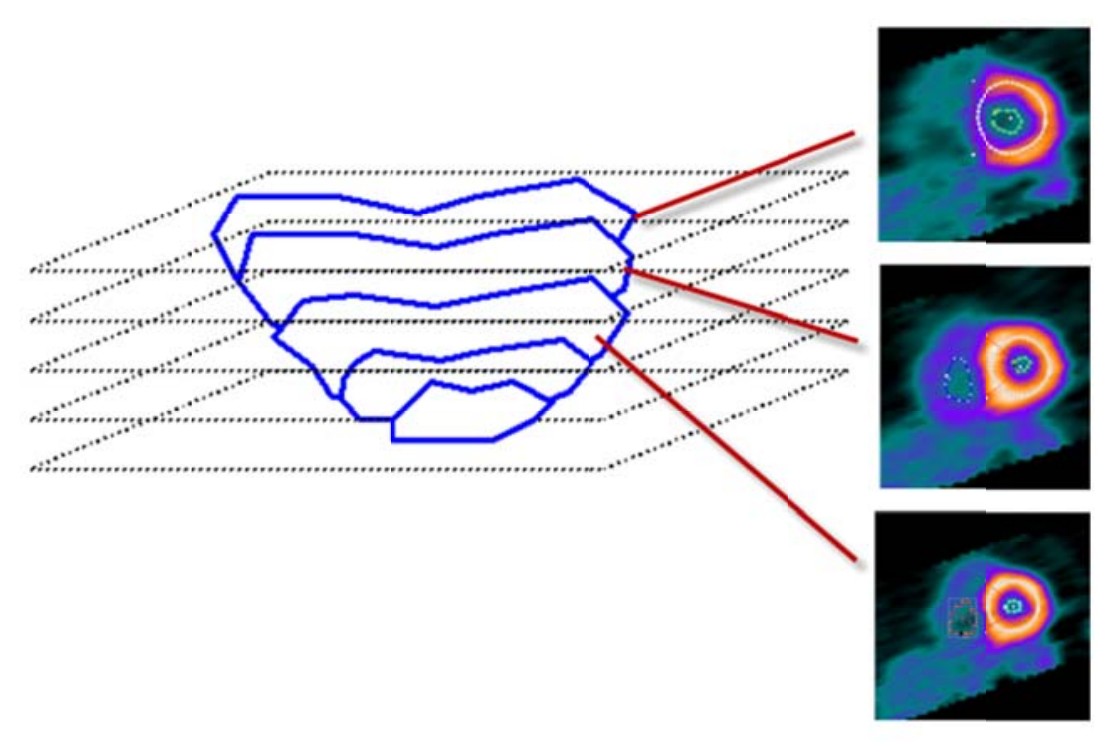

\begin{tabular}{|c|c|c|c|c|c|c|c|}
\hline Parameter & F[STRESS] & & relative & F[REST] & & relative & CFR \\
\hline Segment & $\mathrm{ml} / \mathrm{min} / \mathrm{g}$ & $\mathrm{SD}[\%]$ & [\% of Max] & $\mathrm{ml} / \mathrm{min} / \mathrm{g}$ & $\mathrm{SD}[\%]$ & [\% of Max] & $S / R$ \\
\hline LAD & 2.7067 & & & 0.5584 & & & 4.8 \\
\hline 1. basal anterior & 2.241 & 5.558 & 65.6 & 0.4698 & 8.11 & 70.2 & $4:$ \\
\hline 2. basal anteroseptal & 2.9682 & 7.189 & 86.9 & 0.6267 & 9.342 & 93.6 & 4.7: \\
\hline 7. mid anterior & 2.6552 & 5.789 & 77.7 & 0.4414 & 7.395 & 65.9 & 6.0 : \\
\hline 8. mid anteroseptal & 3.4154 & 7.232 & 100 & 0.6693 & 9.857 & 100 & 5.11 \\
\hline 13. apical anterior & 2.1028 & 4.856 & 61.6 & 0.5084 & 7.072 & 76 & 4.1: \\
\hline 14. apical septal & 3.3762 & 10.316 & 98.8 & 0.6437 & 12.461 & 96.2 & 5.2 \\
\hline 17. apex & 1.8309 & 11.675 & 53.6 & 0.5824 & 15.2 & 87 & 3.1 \\
\hline RCA & 2.5259 & & & 0.4907 & & & 5.1 \\
\hline 3. basal inferoseptal & 2.2166 & 6.901 & 64.9 & 0.5172 & 11.905 & 77.3 & 4.21 \\
\hline 4. basal inferior & 2.2789 & 11.347 & 66.7 & 0.4489 & 16.664 & 67.1 & 5.0: \\
\hline 9. mid inferoseptal & 3.0826 & 7.986 & 90.3 & 0.5781 & 10.506 & 86.4 & $5.3:$ \\
\hline 10. mid inferior & 2.5576 & 10.108 & 74.9 & 0.4574 & 20.535 & 68.3 & $5.5 !$ \\
\hline 15. apical inferior & 2.5673 & 11.345 & 75.2 & 0.4092 & 18.128 & 61.1 & $6.2:$ \\
\hline LCX & 2.3844 & & & 0.5077 & & & $4.6 !$ \\
\hline 5. basal inferolateral & 2.359 & 6.905 & 69.1 & 0.4965 & 11.515 & 74.2 & 4.7! \\
\hline 6. basal anterolateral & 2.1766 & 3.945 & 63.7 & 0.5132 & 4.348 & 76.7 & 4.2 \\
\hline 11. mid inferolateral & 2.9378 & 8.969 & 86 & 0.508 & 14.1 & 75.9 & 5.71 \\
\hline 12. mid anterolateral & 2.3493 & 4.427 & 68.8 & 0.5672 & 5.279 & 84.7 & 4.1 \\
\hline 16. apical lateral & 2.0485 & 6.911 & 60 & 0.4365 & 6.955 & 65.2 & $4.6 !$ \\
\hline GLOBAL & 2.5562 & & & 0.5228 & & & 4.81 \\
\hline
\end{tabular}

Figure 2. Result of the stress and rest MBF and CFR calculations for 17 standard segments. In addition, regional LAD, RCA, LCX and global values are also given.

\subsection{Statistical analysis}

The Passing-Bablok regression scatter diagrams ${ }^{[12]}$ with the regression line (solid line), the confidence interval for the regression line (dashed lines) and identity line ( $\mathrm{x}=\mathrm{y}$, dotted line), were used to show rest and stress results for the 1 and 2 compartmental model. The Bland and Altman method ${ }^{[13]}$ was used to analyze the difference between the 1 compartmental and 2 compartmental model results and to test the repeatability of these results. The repeatability coefficient was calculated as 1.96 times the SD of the differences ${ }^{[14]}$. The data are reported as mean \pm SD. For comparison, the repeatability coefficient is also given as a percentage of the average value of the $1 \mathrm{~cm}$ and $2 \mathrm{~cm}$ model results. 


\section{Results}

For all 29 subjects, the average resting global MBF values for the $1 \mathrm{CM}$ and $2 \mathrm{~cm}$ were $0.74 \pm 0.17$ vs. $0.73 \pm$ $0.18 \mathrm{~mL} / \mathrm{min} / \mathrm{g}$, respectively, with a mean difference of $1.0 \% \pm 4.8 \%(P=$ not statistically significant [NS]). The repeatability coefficient was $0.12 \mathrm{~mL} / \mathrm{min} / \mathrm{g}$ (16.3\% of the mean). The coefficient of correlation was high, 0.94 (see Figure 3). The pharmacological induced stress global average MBF values were significantly higher, $1.73 \pm 0.50$ and $1.71 \pm 0.54$ $\mathrm{mL} / \mathrm{min} / \mathrm{g}$, for the $1 \mathrm{~cm}$ and $2 \mathrm{~cm}$, respectively, with a mean difference of $1.0 \% \pm 4.7 \%(P=\mathrm{NS})$. The repeatability coefficient was $0.25 \mathrm{~mL} / \mathrm{min} / \mathrm{g}$ (14.4\% of the mean). The coefficient of correlation was high, 0.97 (see Figure 3 ).

\section{Global MBF}

\section{Rest}

A

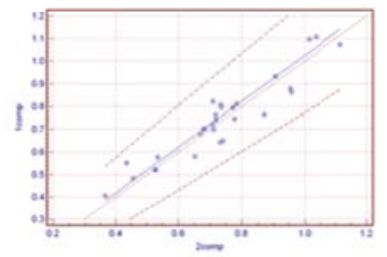

for the regression line (dashed lines) and identity line ( $\mathrm{x}=\mathrm{y}$, dotted line), for global MBF values obtained by $1 \mathrm{~cm}$ and $2 \mathrm{~cm}$ calculations (A) at rest $(n=29$, $r=0.94)$ and (B) at stress ( $n=29, r=0.97)$. Altman-Bland plots for rest (C) and stress (D) global MBF obtained by $1 \mathrm{~cm}$ and $2 \mathrm{~cm}$ calculations, respectively.

\section{C}

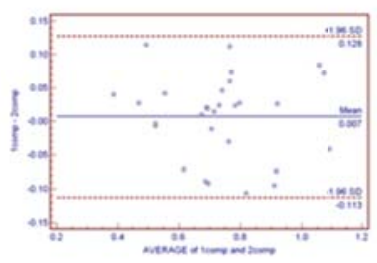

Figure 3. The Passing - Bablok regression scatter diagram with the regression line (solid line), the confidence interval
B

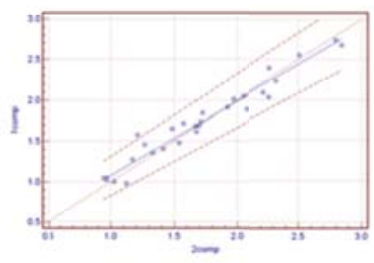

D

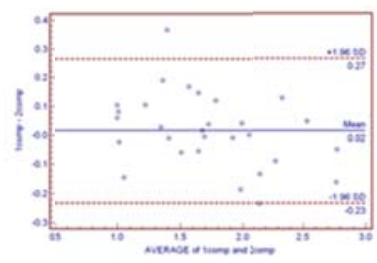

Regional LAD MBF

Rest

A

$\mathrm{C}$
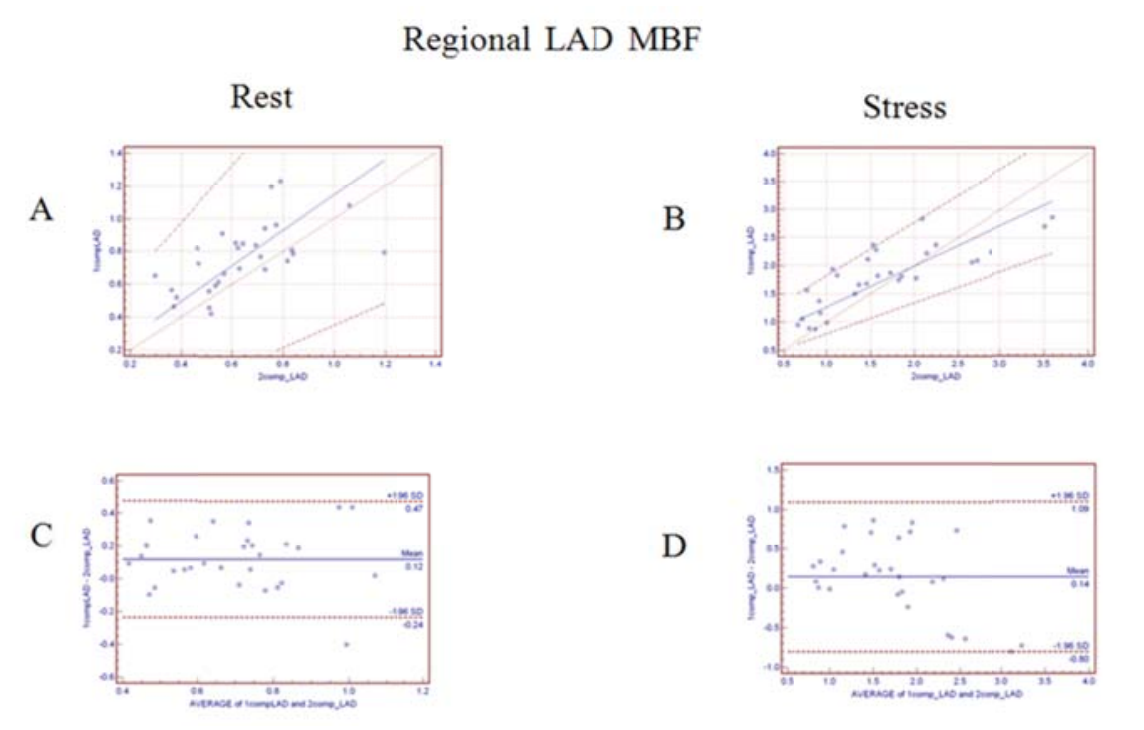

Stress
Figure 4. The Passing -Bablok regression scatter diagram with the regression line (solid line), the confidence interval for the regression line (dashed lines) and identity line ( $\mathrm{x}=\mathrm{y}$, dotted line), for regional $L A D$ MBF obtained by $1 \mathrm{~cm}$ and $2 \mathrm{~cm}$ calculations, (A) at rest $(n=29$, $r=0.60)$ and (B) at stress ( $n=29, r=0.81)$. Altman-Bland plots for the same regional LAD MBF obtained by $1 \mathrm{~cm}$ and $2 \mathrm{~cm}$ calculations, for rest (C) and stress (D), respectively. , respectively.

The regional, LCX, LAD and RCA rest and stress MBF values, obtained by $1 \mathrm{~cm}$ and 2cm, were marginally reproducible, i.e., 50\% or more of the mean. Figure 4 shows Bland-Altman and Passok-Bablock graphs for the LAD region for which, 
resting mean MBF values for the $1 \mathrm{~cm}$ and $2 \mathrm{~cm}$ were $0.76 \pm 0.20$ vs. $0.64 \pm 0.20 \mathrm{~mL} / \mathrm{min} / \mathrm{g}$, respectively, with a mean difference of $18.4 \% \pm 18.5 \%$ ( $P=0.0015)$. The repeatability coefficient was 0.36 ( $52.1 \%$ of the mean). The coefficient of correlation was marginal, 0.60 (see Figure 4). The stress mean MBF values for the $1 \mathrm{~cm}$ and $2 \mathrm{~cm}$ were $1.81 \pm 0.56$ vs. 1.67 $\pm 0.81 \mathrm{~mL} / \mathrm{min} / \mathrm{g}$, respectively, with a mean difference of $8.3 \% \pm 27.80 \%(P=0.1185)$. The repeatability coefficient was 0.95 ( $54.5 \%$ of the mean). The coefficient of correlation was 0.81 (see Figure 4).

The 1CM and 2CM average global CFR values were $2.44 \pm 0.84$ and $2.44 \pm 0.89$, respectively, with a mean difference of $1.9 \% \pm 4.9 \%(P=\mathrm{NS})$. The repeatability coefficient was $0.34(14.1 \%$ of the mean). The coefficient of correlation was high, 0.98 (see Figure 5). The LAD CFR values were $2.49 \pm 0.87$ and $2.72 \pm 1.33$, respectively, with a mean difference of $0.23 \pm 0.46$ or $9.0 \% \pm 17.8 \%$ of the mean $(P=0.1599)$. The repeatability coefficient was $1.72(65.9 \%$ of the mean). Coefficient of correlation was 0.76 (see Figure 5).

\section{CFR}

Figure 5. (A) The Passing -Bablok regression scatter diagram with the regression line (solid line), the confidence interval for the regression line (dashed lines) and identity line ( $\mathrm{x}=\mathrm{y}$, dotted line), for global CFR values obtained by $1 \mathrm{CM}$ and 2CM calculations $(n=29, r=0.98)$ and (B) corresponding Altman-Bland plots. (C) The Passing -Bablok regression scatter diagram ( $n=29, r=0.76$ ) for regional LAD CFR obtained by $1 \mathrm{~cm}$ and $2 \mathrm{~cm}$ calculations and (D) corresponding Altman-Bland plot for regional LAD CFR obtained by $1 \mathrm{~cm}$ and $2 \mathrm{~cm}$ calculations.
A

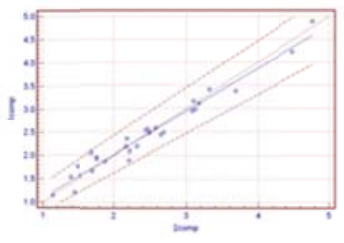

$\mathrm{C}$

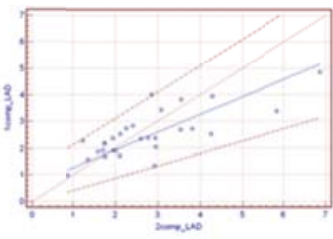

B

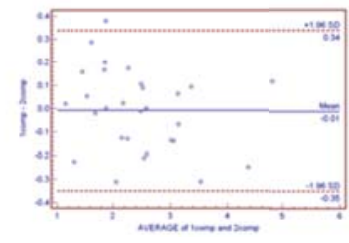

D

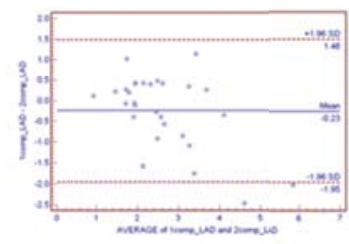

\section{Discussion}

To the best of our knowledge, this is the first study to compare $1 \mathrm{~cm}$ and $2 \mathrm{~cm}$ calculations of global and regional MBF and CFR values for ${ }^{82} \mathrm{Rb}$ myocardial perfusion PET imaging. A similar study was performed for ${ }^{13} \mathrm{NH}_{3}$ myocardial perfusion PET imaging. Three approaches, two using $2 \mathrm{~cm}$ and one using $1 \mathrm{~cm}$, were compared ${ }^{[6]}$, and preference was given to the $1 \mathrm{~cm}$ approach. However, one cannot find in the literature the most preferable approach to calculations of MBF in ${ }^{82} \mathrm{Rb}$ PET perfusion studies. Not long ago, in a comparison of flow estimates obtained by ${ }^{13} \mathrm{NH}$-ammonia and by ${ }^{82} \mathrm{Rb}$, done by the Ottawa group ${ }^{[7]}$, the $2 \mathrm{CM}$ was used for MFB calculations in $13 \mathrm{NH}$-ammonia studies and the $1 \mathrm{~cm}$ approach was used for 82Rb MBF calculations. As a result there is still ambiguity in the choice of approach for estimation of MBF in PET perfusion studies, using either ${ }^{13} \mathrm{NH}$-ammonia or ${ }^{82} \mathrm{Rb}$.

In January 2009, two studies presenting repeatability of MBF in ${ }^{82} \mathrm{Rb}$ PET myocardial imaging were reported. The first study ${ }^{[15]}$ used a $1 \mathrm{~cm}$ approach and was limited to only global MBF rest and stress values and concluded that MBF and CFR using ${ }^{82} \mathrm{Rb}$ were highly reproducible. The second study ${ }^{[16]}$ used a $2 \mathrm{~cm}$ approach utilizing of Daubechies wavelets for temporal smoothing. The conclusion of the study was that global MBF and CFR were highly reproducible. For regional MBF and CFR values, reproducibility was, for the majority of the segments, was also very good. However, without wavelets temporal smoothing, the regional MBF and CFR values were marginally reproducible. Recently, generalized factor analysis has also been used to improve ${ }^{82} \mathrm{Rb}$ PET myocardial imaging ${ }^{[17]}$, resulting in excellent reproducibility of MBF in ${ }^{82} \mathrm{Rb}$ PET studies. Also, the accuracy of the absolute quantization of MBF in comparison with ${ }^{13} \mathrm{NH}$-ammonia study was very good. However, the limitation of the study was a relatively limited number of subjects, 22, and few subjects 
had documented CAD and none with evidence of stress perfusion defects. The segmental MBF values were also presented and discussed.

The results of these relatively recent studies ${ }^{[15-17]}$ showed that in ${ }^{82} \mathrm{Rb}$ PET imaging, global MBF and CFR values are reproducible, regardless of whether a $1 \mathrm{~cm}$ or $2 \mathrm{~cm}$ approach was used. Temporal smoothing or using factorial analysis to address relatively noisy dynamic ${ }^{82} \mathrm{Rb}$ data, especially the late frames, due to the short half-life of $75 \mathrm{~s}$, improves the repeatability of MBF and CFR calculations for global and regional values.

In our approach, further improvement of assessing ${ }^{82} \mathrm{Rb}$ rest and stress MBF values and CFR can be obtained by allowing creation of the input TAC using the left atrial (LA) area in addition or instead of the LV cavity area. In some subjects with a small heart, a small LV cavity may not be the best choice for creating the input TAC, due to high cross talk from the LV wall activity. However, for real improvement in accuracy of regional and segmental MBF and CFR calculations, one would also need to apply cardiac and breathing gating. To the best of our knowledge, none of the current studies have done so.

\section{Conclusions}

The results of the study suggest that in ${ }^{82} \mathrm{Rb}$ perfusion myocardial PET assessment of MBF and CFR, the global rest and stress MBF and CFR values obtained by $1 \mathrm{~cm}$ or $2 \mathrm{~cm}$, were close and reproducible. However, the regional LAD, RCA and LCX rest and stress MBF values showed marginal reproducibility. Limited regional MBF reproducibility may be caused by sampling error and/or cardiac and breathing motion. The results also suggest that both, $1 \mathrm{~cm}$ and $2 \mathrm{~cm}$ are equally accurate for calculation of MBF and CFR global values in ${ }^{82} \mathrm{Rb}$ perfusion myocardial PET studies.

\section{Conflicts of interest}

The authors declare that they have no conflict of interest.

\section{References}

[1] Kaufmann PA. 82Rubidium-the dawn of cardiac PET in Europe? Eur J Nucl Med Mol Imaging. 2007; 34:1963-64. PMid: 18034240. http://dx.doi.org/10.1007/s00259-007-0632-x

[2] J. Knuuti. Should we use more PET-CT in clinical cardiology? Eur J Nucl Med Mol Imaging. 2008; 35:887-88. PMid: 18317753. http://dx.doi.org/10.1007/s00259-008-0741-1

[3] Yalamanchili P, Wexler E, Hayes M, Yu M, Bozek J, Radeke H, et al. Mechanism of uptake and retention of 18F BMS-747158-02 in cardiomyocytes: A novel PET myocardial imaging agent. J Nucl Car. 2007;14(6):782-8. PMid: 18022104. http://dx.doi.org/10.1016/j.nuclcard.2007.07.009

[4] Kaufmann PA, Camici PG, Myocardial Blood Flow Measurement by PET: Technical Aspects and Clinical Applications. J Nucl Med. 2005; 46: 75-88. PMid: 15632037.

[5] Knešaurek K, Machac J, Krynyckyi BR, Almeida OD. Comparison of 2D and 3D 82Rb myocardial perfusion PET imaging. J Nucl Med. 2003; 44: 1350-56. PMid: 12902427.

[6] DeGrado TR, Hanson MW, Turkington TG, Delong DM, Brezinski DA, Vallee JP, et al. Estimation of myocardial blood flow for longitudinal studies with 13N labeled ammonia and positron emission tomography. J Nucl Cardiol. 1996; 3: $494-507$. http://dx.doi.org/10.1016/S1071-3581(96)90059-8

[7] Lortie M, Beanlands RSB, Yoshinaga K, Klein R, DaSilvaJN, DeKemp RA. Quantification of myocardial blood flow with ${ }^{82}$ Rb dynamic PET imaging. Eur J Nucl Med MolImag. 2007; 34: 1765-74. PMid: 17619189. http://dx.doi.org/10.1007/s00259-007-0478-2

[8] Herrero P, Markham J, Shelton ME, Weinheimer CJ, Bergmann SR. Noninvasiv equantification of regional myocardial perfusion with rubidium-82 and positron emission tomography: exploration of a mathematical model. Circulation. 1990; 82:1 377-86.

[9] Herrero P, Markham J, Shelton ME, Bergmann SR. Implementation and evaluation of a two-compartment model for quantification of myocardial perfusion with rubidium-82 and positron emission tomography. Circ Res. 1992; 70: 496-507.

PMid: 1537087.

Published by Sciedu Press 
[10] Dimitrakopoulou-Strauss A, Strauss LG, Schwarzbach M, Burger C, Heichel T, Willeke F, et al. Dynamic PET 18F-FDG Studies in Patients with Primary and Recurrent Soft-Tissue Sarcomas: Impact on Diagnosis and Correlation with Grading. J Nucl Med. 2001; 42: 713-20. PMid: 11337565.

[11] Wyss CA, Koepfli P, Mikolajczyk K, Burger C, Schulthess GK, Kaufmann PA. Bicycle exercise stress in PET for assessment of coronary flow reserve: repeatability and comparison with adenosine stress. J Nucl Med. 2003; 44:146-154. PMid: 12571202.

[12] Passing H, Bablok W. A new biometrical procedure for testing the equality of measurements from two different analytical methods. Application of linear regression procedures for method comparison studies in Clinical Chemistry, Part I. J. Clin. Chem. Clin. Biochem. 1983; 21: 709-20. PMid: 6655447.

[13] Bland JM, Altman DG. Statistical methods for assessing agreement between two methods of clinical measurement. Lancet. 1986; 327: 307-10. http://dx.doi.org/10.1016/S0140-6736(86)90837-8

[14] Precision of Test Methods. I: Guide for the Determination and Reproducibility for a Standard Test Method. London, U.K.: British Standards Institution. 1976; 54-97.

[15] Manabe O, Yoshinaga K, Katoh C, Naya M, deKemp RA, Tamaki N. Repeatability of rest and hyperemic myocardial blood flow measurements with ${ }^{82} \mathrm{Rb}$ dynamic PET. J Nucl Med. 2009; 50: 68-71. PMid: 19091892. http://dx.doi.org/10.2967/jnumed.108.055673

[16] Knešaurek K, Machac J, Zhang Z. Repeatability of regional myocardial blood flow calculation in ${ }^{82} \mathrm{Rb} \mathrm{PET}$ imaging. BMC Medical Physics. 2009; 9:2. http://www.biomedcentral.com/1756-6649/9/2

[17] El Fakhri G, Kardan A, Sitek A, Dorbala A, Abi-Hatem N, Lahoud Y, Fischman A, Coughlan M, Yasuda T, Di Carli MF. Reproducibility and accuracy of quantitative myocardial blood flow assessment with ${ }^{82} \mathrm{Rb}$ PET: Comparison with $13 \mathrm{~N}$-Ammonia PET. J Nucl Med. 2009; 50:1062-71. PMid: 19525467. http://dx.doi.org/10.2967/jnumed.104.007831 